\title{
TRADUCCIÓN Y DIFUSIÓN DEL LIBRO DE LOS SECRETOS DE AGRICULTURA DE MIGUEL AGUSTÍN (1749). LÉXICO Y CONOCIMIENTO VITIVINÍCOLA ${ }^{1}$
}

\author{
Miguel IbÁÑez Rodríguez \\ Universidad de Valladolid \\ miguel.ibanez@uva.es
}

\begin{abstract}
Resumen: En este artículo se estudia el léxico de la vid y el vino en el libro tercero de los Secretos de Agricultura de Miguel Agustín, escrito en catalán en 1617 y después vertido al español en 1626. También se revisa la traducción y difusión de dicho tratado. Se concluye que, en comparación con el tratado de 1513 de G. Alonso de Herrera, hay mayor pobreza terminológica y sus aportaciones a la lengua del vino no son significativas, a pesar de que introduce voces nuevas, pero que no llegan a consolidarse, y de su mayor densidad terminológica en los tipos de vinos y en la cata.
\end{abstract}

Palabras clave: Secretos de Agricultura, Miguel Agustín, traducción, vino, léxico.

Title: Translation and spreading of Libro de los Secretos de Agricultura by Miguel Agustín (1749). Wine lexicon and knowledge.

\begin{abstract}
This paper addresses the wine lexicon in the third book of Secretos de Agricultura (Agricultural secrets), by Miguel Agustín, first written in Catalan in 1617 and then translated into Spanish in 1626. The translation and spreading of the said treatise are also covered here. A comparison with a previous treatise by G. Alonso de Herrera (1513) reveals that terminology in Agustín's book is not as rich as Alonso de Herrera's and its contribution to wine language is not significant, despite the introduction of some new words that never consolidated and a higher terminological density regarding wine types and tasting.
\end{abstract}

Keywords: Secretos de Agricultura, Miguel Agustín, translation, wine, lexicon.

1 Este artículo se ha realizado en el marco del Proyecto de I+D de la Junta de Castilla y León de referencia VA102G19 y titulado «La lengua de la vid y el vino y su traducción». 


\section{INTRODUCCIón}

Con el libro segundo de la Obra de agricultura de 1513 de G. Alonso de Herrera se establece lo que es el primer vocabulario especializado sobre el vino en español (Ibáñez, 2020). Más adelante, a finales del siglo XVIII y primera mitad del siglo XIX va apareciendo otra corriente con la que se incorpora al español del vino un léxico más científico que llega desde Francia con la nueva ciencia, la enología (Ibáñez, 2017). Entre tanto, ¿qué ocurre?

La continuidad de la corriente iniciada por G. Alonso de Herrera queda garantizada por las sucesivas y muy numerosas ediciones que se hacen de su obra hasta el siglo XIX. Quirós (2015) anota veintidós hasta dicha centuria. Aquí, lo que pretendemos es estudiar el libro tercero del Libro de los Secretos de Agricultura de Miguel Agustín para saber si queda dentro de la corriente iniciada por G. Alonso de Herrera o no y si hace aportaciones nuevas al español del vino. Este texto es otro hito en el conocimiento enológico y no podía quedar sin ser estudiado. ¿Hay ya influjo francés en el léxico del vino de este tratado escrito en catalán en 1617 sirviéndose de fuentes francesas y luego traducido al castellano en 1626 por su propio autor?

Trataremos con este trabajo de dar respuesta a las peguntas planteadas. Con ese propósito vamos a estudiar el léxico del vino del tratado de Miguel Agustín y el conocimiento vitivinícola que recoge, en particular en su libro tercero, dedicado a la vid y al vino. Lo hacemos comparándolo con el libro segundo del tratado de 1513 de G. Alonso de Herrera, referente entonces en la materia. Para contextualizar nuestro estudio, explicaremos la génesis, traducción y difusión de la obra de Miguel Agustín y también sus fuentes y contenido. No contemplamos el hacer un estudio contrastivo entre el original francés y la obra de Miguel Agustín, cosa que ya ha hecho Luna-Batlle (2017 y 2018), del que partimos.

Para el presente trabajo nos hemos servido de un ejemplar del Libro de los Secretos de Agricultura de Miguel Agustín de la edición de 1749, conservado en la Biblioteca del Monasterio de San Millán de la Cogolla, en La Rioja. Cuando comparamos este tratado con la Obra de agricultura de G. Alonso de Herrera lo hacemos con la edición de 1539 por ser la última revisada por el autor, publicada el 8 de junio de ese año en Alcalá de Henares por Joan de Brocar. Hemos consultado el ejemplar conservado en el Centro de Documentación Vivanco Cultura del Vino, situado en Briones, La Rioja.

Contribuimos con este trabajo a conocer mejor la historia del conocimiento en España, en particular de lo que hoy se llama las ciencias de la vid y el vino, y aportamos datos para la historia de la lengua de la vid y el vino. También resulta de interés nuestro trabajo porque, por otro lado, recuperamos patrimonio cultural inmaterial dando más visibilidad a voces patrimoniales, técnicas, operaciones y tradiciones encerradas en tratados que desempolvamos. 


\section{TRADUCCIón Y DIFUSIóN}

En 1617 vio la luz por primera vez en catalán, publicado en Barcelona por Esteve Lliberós, el libro de Miguel Agustín titulado Secrets de agricultura, casa rústica y pastoril. Miquel Agustí, conocido en español como Miguel Agustín, nació en Banyoles probablemente en 1560 y murió en 1630 posiblemente en Perpiñán. Fue prior de la orden de San Juan de Jerusalén en Perpiñán, entre 1602 y 1630, y agrónomo, que debe su celebridad al libro que aquí nos ocupa. El tratado no se volvió a publicar en catalán. En 1998 y en 2007 se editaron sendas ediciones facsimilares.

Fue el propio Miguel Agustín el que, pocos años después de la primera edición en catalán, decidió traducir y editar en 1626 una versión del libro en castellano. Se publicó en Perpiñán, a cargo de Luis Roure Librero, con el título de Libro de los secretos de agricultura, casa de campo y pastoril traducido de lengua Cathalana en Castellano, añadiendo un quinto libro, otras curiosidades y un vocabulario en seis lenguas. Así lo explica el propio Agustín (1749) al final del prólogo:

Por esto, y por hallarme inclinado a dicha profesión; y tener algunas experiencias de ella, me ha parecido emplear algunas vigilias, y ratos de tiempo, particularmente estando desocupado de los negocios de la Iglesia, en tomar trabajo de recopilar en lengua Castellana el libro, que saqué a la luz en lengua cathalana el año 1617 y ahora va añadido en esta impresión el Quinto Libro, y algunas otras curiosidades, y un Vocabulario en seis Lenguas, de los nombres Castellanos de los árboles, frutas, yerbas, y otras cosas nombradas en dicho Libro, para que mejor las otras lenguas se puedan valer del; con el cual Libro hallarán modos, y trazas para encaminar...

Con el paso del tiempo esta versión en castellano conoció un gran número de ediciones, hasta veinte según recoge Luna-Batlle (2013: 66). Antón, en su Diccionario de bibliografía, publicado en 1865 , ya anotaba que ya se habían hecho «por lo menos once ediciones» (p. 856) del «Libro o la agricultura del Prior», que es así como «vulgarmente se designa a esta obra» (Antón, 1865: 214). Estas son las ediciones que anota Antón: la primera en catalán en 1617, otra en Zaragoza de 1625, otra en Perpiñán de 1626, otras dos en Zaragoza, en 1636 y 1702, otra en Barcelona en 1722, otra en Madrid en 1731, otra en Zaragoza en 1746, otra en Barcelona en 1749 y, por último, dos en Madrid, en 1762 y en 1781. En total once.

No está entre los objetivos de este trabajo el recopilar todas las ediciones, de lo que, por otro lado, ya se ha ocupado Soberanas (1988) y después Pablo Núñez 
(2007-2008). Del siglo xvir Pablo Núñez (2007-2008: 206-207) anota cinco y once del siglo XVIII, cuando más se imprimió.

La traducción castellana es en realidad la traducción de una traducción, pues el original catalán no es tal. Luna-Batlle (2017: 111) señala que el Llibre dels secrets de agricultura, casa rústica y pastoril es en su mayor parte la traducción de la obra francesa de agricultura titulada $L$ 'Agriculture et maison rustique de Charles Estienne y Jean Liébault. Esta circunstancia ya la había advertido antes Luis Pablo Nuñez (2007-2008: 202), quien, a su vez, lo recoge de la publicación Bibliotheca Mágica (2007: 121).

\section{ConTENido y FUENTES}

Los 200 folios del libro del Prior se centran fundamentalmente en la agricultura, pero también se ocupa de la veterinaria, de la medicina, de la destilación de licores, de agrimensura, de la gestión de la actividad agrícola y de geografía económica. El contenido relativo a la vid y al vino aparece en los cuatro primeros capítulos del libro tercero.

En palabras de Luna-Batlle (2017: 112), el libro tiene una doble función, por un lado, es un libro práctico sobre la agricultura, los animales y la gestión de una casa de campo y, por otra, es un libro doctrinal. Dada la condición religiosa del autor, este presenta un modelo de vida agrícola acorde con las creencias cristianas. Muchas de las prácticas agrícolas recogidas se han mantenidos con pocas variaciones hasta los años 60 y 70 del siglo pasado. No ocurre lo mismo con el tratamiento de las enfermedades de personas, animales y plantas, que desde la perspectiva actual se presentan como rudimentarias y muy superadas. Lo mismo ocurre con las costumbres o modelo de vida, en el que, por ejemplo, los papeles de la mujer y del hombre responden a una visión muy tradicionalista que las generaciones que nos han precedido han conocido. El hombre asume las tareas de los dineros, la compra y venta de bienes y la mujer de los animales, hortalizas y tareas de la casa.

Sorprende que Miguel Agustín no tenga en cuenta entre sus fuentes la Obra de agricultura del humanista Alonso de Herrera, la más conocida y de más amplia tradición y difusión en España, publicada por primera vez en 1513, mucho antes que el tratado catalán, y pionero en Europa entre las lenguas vernáculas. Luna-Batlle (2017: 113-114) manifiesta que desconoce las razones por las que no cita Miguel Agustín a Alonso de Herrara y tampoco al gran geópono francés Olivier de Serres, que había escrito su tratado en 1600, 17 años antes que el del catalán, con el título 
de Le théatre d'agriculture et mesnage des champs ${ }^{2}$. Se inaugura con él en Francia un nuevo tiempo para los textos agronómicos. Olivier de Serres es el padre de la agronomía en Francia, lo que había sido Alonso de Herrera años antes en España. Se trata, sin duda, de dos ausencias notables.

¿Si no se sirve de los dos geóponos de referencia en España y en Francia, de qué otros autores toma el contenido de su tratado? Luna-Batlle (2017: 114), con relación a la primera edición del texto en catalán, señala que el autor más citado, con 88 menciones, es Esteve, en 6 casos citado junto a Joan Llibaut. Se trata de los franceses Charles Estienne y Jean Liébault. El segundo autor por número de menciones es Mizaldo, con 54, en francés Antoine Mizauld. En el folio IV verso en su primera edición en catalán Miguel Agustín anota los autores que cita, entre los que hay un buen número de la Antigüedad Clásica, entre ellos Columela, Plinio, Teofrasto, Varrón o Virgilio. Cuando los cita, los pone al margen del texto y al final hace la citada relación de todos ellos. Luna-Batlle (2015: 27), siguiendo a Emili Giralt, señala que los 80 autores referidos por Miguel Agustín como fuentes es más para impresionar al lector y para dar prestigio a su obra. Y parece evidente que no los ha leído todos.

Se cita con cierta frecuencia a Rutilio Tauro Emiliano Paladio, escritor y agrónomo romano del siglo IV, más conocido como Paladio. Es autor de Opus agriculturae o De re rustica, texto muy modificado durante la Edad Media y que contó con gran difusión y prestigio. Alonso de Herrera en su tratado lo cita también, de igual modo que Pedro Crescenzi.

Más allá de estas citas explícitas, Luna-Batlle (2017: 114) indica que, aunque Miguel Agustín no lo dice, una gran parte del libro es traducción o una versión más o menos libre o adaptada de textos anteriores franceses. Estos básicamente son la Maison rustique de Charles Estienne y Les XX livres de Constantin Cesar, ausquelz sont traictez les bons enseignements d'agriculture de Casianus Basus.

Charles Estienne (1504-1564) escribió varios libros de agronomía (Luna-Batlle, 2017: 116). El primero de ellos en latín es de 1554 y lleva el título de Praedium Rusticum. Esta obra se traduce al francés con el título de Maison rustique en 1564, año de la muerte del autor. En 1570 aparece una versión ampliada con la colaboración de Jean Liébault, su yerno, que interviene de manera importante, de modo que se puede considerar coautor, a pesar de que su nombre no aparece en la portada (Luna-Batlle, 2017: 116). La tercera versión francesa, ampliada y en cuya portada ya aparecen los dos autores, es de 1586.

2 Hemos podido consultar una edición de 1611, que anotamos en las referencias bibliográficas. 
Hay otra edición de 1597 que es prácticamente idéntica a la de 1586 y, salvando algunos detalles tipográficos y ortográficos, a la posterior de 1600 , de la que se conserva un ejemplar en la biblioteca de la Universidad de Barcelona. Hemos podido consultar una edición de 1594 y la de 1597, ambas disponibles en línea y que recogemos en las referencias bibliográficas.

¿Qué edición consultó Miguel Agustín? Luna-Batlle (2017: 116-117), tras realizar un análisis comparativo concluye que la de 1570, ya que Miguel Agustín recoge todas sus ampliaciones. Ahora bien, no puede afirmar que esta sea la única edición utilizada, ya que al citar al margen, Miguel Agustín diferencia entre citar solo a Charles Estienne («Esteve») y a este junto a Liébault («Esteve-Libault»), en este último caso en un número mucho menor. Y la coautoría tal como hemos anotado solo aparece en ediciones posteriores.

Con relación al texto de Charles Estienne, Miguel Agustín al traducir adapta y suprime a su conveniencia, tergiversa o practica una traducción servil, tal como anota Luna-Batlle (2018: 122). Los grabados del libro de Miguel Agustín en su mayoría son copiados de Maison rustique de Charles Estienne.

Si bien en el título del libro en castellano se dice «traducido», en el prólogo del mismo se habla de «recopilar», tal como se recoge en la cita del prólogo arriba reproducida. En el título de la primera edición en catalán se anota «[...] recopilat de diversos autors, antichs y moderns, de llenguas llatina, italiana, y francesa [...] ». Parece que Miguel Agustín interpreta de igual modo traducir que recopilar, se plantea el texto original como fuente de la nueva publicación. Así lo hace con el texto de Charles Estienne y con el de su primera edición en catalán al verterlo al castellano.

La segunda fuente utilizada por Miguel Agustín es, según anota Luna-Batlle (2017: 117), Les XX livres de Constantin Cesar, ausquelz sont traictez les bons enseignements d'agriculture con ediciones en Poitiers (1545), Lyon (1550, 1597) y París (1550). Se trata de un texto de Casianus Basus traducido al francés por Anthoine Pierre desde la versión latina de J. Cornario, que recogía escritos agronómicos griegos clásicos. Se desconoce de qué edición se sirvió Miguel Agustín, pero seguramente fue de alguna de las muchas versiones francesas que circulaban en su tiempo. Por esta vía llegan al tratado de Miguel Agustín muchos de los mitos y creencias supersticiosas relacionadas con el mundo agrario, la medicina y la veterinaria, apunta Luna-Batlle (2017: 117).

Luna-Batlle (2015: 23) indica que el segundo autor más citado por Miguel Agustín es Antoine Mizauld (1520-1578). Se trata de un astrólogo y médico francés que se interesó por las ciencias ocultas y la alquimia y fue autor de numerosas obras en latín sobre esta temática y sobre botánica, con traducciones a diversas lenguas. 
El «secretismo» de la obra de Miguel Agustín le viene de él, señala Luna-Batlle. La palabra secreto aparece desde el mismo título del libro de Miguel Agustín. Lo hace con el significado de «cómo proceder» en materia agrícola.

En definitiva, Miguel Agustín, sin hacer una valoración crítica y seguramente sin conocer la calidad de los tratados de agronomía que circulan en su época, recurre al de Charles Estienne y otros, que es lo que posiblemente tiene más a mano en su monasterio. Eso y el contexto en el que escribe hacen que en su obra esté presente lo supersticioso, procedente del mundo clásico y de la Edad Media, que ya se ha desterrado en parte en otros tratados, como el de Olvier de Serres, y propicia que su trabajo carezca del componente técnico que ya tenía el de Alonso de Herrera, escrito años antes. Todo esto tiene su incidencia en el vocabulario especializado utilizado.

\section{LÉXICO Y CONOCIMIENTO VITIVINÍCOLA}

El «vocabulario en seis lenguas» que se incorpora a la obra con la primera edición en castellano de 1626 incluye las siguientes lenguas: español, catalán, latín, portugués, italiano y francés. Contiene este glosario casi 1.600 términos, 266 por cada lengua, sin equivalencia en algunos casos para el italiano y el francés. La inclusión de este vocabulario permite que la obra trascienda lo local para alcanzar una mayor difusión (Pablo Núñez, 2007-2008: 2004).

Se trata, tal como anota Agustín (1749) en el prólogo, «de un vocabulario en seis lenguas de los nombres castellanos de los árboles, frutas, yerbas, y otras cosas nombradas en dicho libro para que mejor las otras lenguas se puedan valer de él». Es un vocabulario de toda la obra, que apenas recoge voces del vino. Las únicas que se anotan son: agraz, heces, uva y vid. La lectura pormenorizada de las partes del libro dedicadas a la vid y al vino, en particular el libro tercero, nos ha permitido extraer la terminología vitivinícola en su contexto y valorar el conocimiento técnico que conceptualiza, por comparación con el tratado de G. Alonso de Herrera (1539). También hemos recogido algún término vitivinícola, como aloque, en otros capítulos no incluidos en el libro tercero.

\subsection{El cultivo de la vid y la elaboración del vino y su léxico}

El tratado de Miguel Agustín en su versión en castellano consta de cinco libros. El primero versa sobre el padre y madre de familia de la casa de campo, de los hijos y criadas, así como de la distribución de tareas por meses y los huertos. El segundo se ocupa de los árboles frutales, de la labranza de las tierras, de los trigos y legumbre, del 
estercolar y de los prados. El tercero trata de las viñas, de la recolección de las uvas, de hacer los vinos, del olivo y del aceite, de la destilación y del medir las tierras. El cuarto libro del sitio y fabricación de la casa de campo, de la cría de los animales domésticos, de las abejas y gusanos de seda. El quinto incluye la cría y adiestramiento de los perros de caza, la caza y la pesca. Tras este quinto libro, está el citado vocabulario en seis lenguas y seguido una rueda perpetua para hallar los años fértiles y estériles.

Tras los libros primero y segundo, llegado el tercero «ahora se trata en este capítulo primero de las viñas, de las cuales, según el tiempo, entra mucho provecho, y riqueza al padre de familia de la casa de campo [...]» (Agustín, 1749: 191). El título del capítulo reza así: «Secretos de las tierras para las viñas y de los sarmientos, y otras particularidades de su administración». En él se explica la necesidad de saber qué tierra es la más conveniente para la viña, la elección de los buenos sarmientos para plantar y se recomienda que sea directamente el padre de familia el que se ocupe de las vinas y no se las deje a los labradores (Agustín, 1749: 192). Aunque este primer capítulo se ciñe, según indica su título, a la plantación de la vid, abarca otros aspectos como la poda, cavar y arar, estercolar, poda en verde y cómo recoger las uvas para conservar.

En cuanto a la tierra para la viña, se ha de tener en cuenta su calidad, su exposición al sol y que «no sea demasiado fuerte, ni gruesa, ni demasiado ligera, ni menudita [...]» (Agustín, 1749: 192-193). Se explica también qué tipo de vid se ha de poner en función de las características de la tierra: así, si se trata de tierra «gorda y fértil», se recomienda la planta de «sarmiento pequeño»; si, por el contrario, se trata de «tierra estéril», se procurará poner «sarmiento fértil» (Agustín, 1749: 193). En los lugares húmedos no se deben plantar vides que produzcan uvas tiernas y gruesas, se recomienda en estos casos las que tienen el grano duro y pequeño (Agustín, 1749: 193).

Se advierte de que la viña no se debe plantar de grano, «porque siempre serían las uvas agrazones, y tardarían mucho en llevar fruto» (Agustín, 1749: 194). Se explica que hay dos maneras de plantar, en ambos casos se trata de hacer un hoyo en el que se introduce el sarmiento, con la diferencia de que en uno de los casos se introducen dos para garantizar que si no es el uno sea el otro el que prenda. Este segundo método se describe así:

En otros territorios el plantar de las viñas es, haciendo hoyos en la tierra, de largo de dos pies y medio, y de ancho un pie poco más, y de hondo un pie y medio, según la hondaría de la tierra, y en cada uno de dichos hoyos ponen dos sarmientos, puestos como la cruz, o aspa de San Andrés, sacando el uno la punta en una parte del hoyo, y el otro de la otra parte, y vuelven la tierra encima los 
sarmientos, pisándola muy bien con un palo, y con los pies; y esto de poner dos en un hoyo se hace, porque cuando en algunos lugares se mueren, sacan uno de las partes donde han vivido los dos, y lo ponen en el lugar donde falta, y esto no se debe trasplantar que no tenga dos años, a fin de que las raíces estén más firmes, y es hacerlo al seguro, y de esta manera la viña está presto en su sazón. La viña tarda cuatro años a empezar a dar fruto; $y$ tiene de vida treinta años en perfección, y es muy duradera, si no tiene desgracia en ser maltratada (Agustín, 1749: 194).

Se señala la conveniencia de que en cada parcela se plante la misma suerte de vides, ya que de lo contrario en la vendimia se recogerán uvas con diferente grado de maduración y el vino de ellas obtenido no será bueno (Agustín, 1749: 194). Para plantar se debe tener en cuenta los ciclos lunares, los sarmientos se han de cortar dos días antes de la luna llena y la plantación se ha de hacer en luna llena (Agustín, 1749: 195).

Hasta este momento (1749: 191-196) todo lo explicado en este capítulo estaba relacionado con la plantación de la vid. Tras anotar la conveniencia de cortar los sarmientos de las vides plantadas se pasa a la poda. Sobre lo primero se dice que se ha de hacer el segundo o tercer año después de plantadas «dejando un ojo o botón encima de la tierra, descalzando el sarmiento: y la cortadura la haréis tres dedos encima del ojo, de modo que el corte se haga al contra de la yema, para evitar que cuando salga la savia en caso de helada no la estropee» (Agustín, 1749: 196).

Sobre la poda se anota:

El podar de las viñas, o sea en diciembre, o en enero, si fueren viñas jóvenes deben ser podadas en luna vieja, y después de hecho el lleno, hasta la conjunción, y también las vides de los parrales; pero las viñas viejas, y las vides viejas de los parrales, conviene hacerla podar de tres en tres, $u$ de cuatro en cuatro años, en luna creciente: esto es después que ha hecho el primer cuarto, hasta el lleno. El podar en luna vieja hace las uvas gruesas, y bellas, y los sarmientos de la misma manera, y el podar en luna nueva hace muchas uvas pequeñas, largos, y delgados los sarmientos (Agustín, 1759: 196).

Se vuelve a la plantación, en este caso para suplir una falta mediante un $m u$ grón. Se trata de una rama de una cepa que se entierra en la fila para remediar una falta. Al enterrarla genera raíces y da lugar a una nueva cepa donde había una falta o marra. De los mugrones se dice que se deben de hacer en luna vieja. 
Se pasa a continuación a explicar otra tarea: el arar y cavar la viña. Se tiene que ejecutar en febrero, la segunda cava corresponde hacerla en abril hasta mediados de mayo y la tercera por junio. Se recomienda no arar ni cavar en los meses calurosos de julio y agosto para no secar la viña (Agustín, 1749: 196-197).

Sobre la conveniencia o no y del momento de estercolar también se habla: «Las viñas se pueden estercolar cuando son nuevamente plantadas, y después de seis en seis años» (Agustín, 1749: 197). También se aconseja el abono vegetal, citando a Paladio:

Mas dice, que el mejor estercolar de las viñas, es sembrar en ellas altramuces en el mes de septiembre, o en la fin de abril, hacia mediado mayo; y cuando los altramuces hicieren segundas flores, los desarraigáis de la tierra, y haréis arar la viña, de manera que ellos queden cubiertos de tierra, y eso sirve de buen estiércol, y engorda mejor la tierra, y en los mugrones cuando se hacen es bueno poner montones de estiércol de bueyes, o bacas, y no de caballeriza, ni de ganado, ni de puercos, que harían más daño que provecho, porque corrompen el vino, y hacen que las viñas sean de poca dura (Agustín, 1749: 197).

Está presente la poda en verde, en concreto la de eliminar los brotes de la madera vieja que no dan fruto y que hoy se llama espergurar y que en el texto se dice pimpollear, pues a los brotes se les llama pimpollos. Para hacer esta tarea hace falta cierto conocimiento técnico.

En el principio de mayo se debe ir a las viñas a quitar los pimpollos de las vides, todos aquellos donde no habrá uvas, y aquellos que puedan servir para hacer mugrones para el siguiente año, y los pimpollos, y uvas que quedarán serán mejores, y eso lo debe hacer hombre que entienda de poda (Agustín, 1749: 197).

Hoy en día no se quitan los zarcillos, a los que se llama cordeles, lo que parece que sí se hacía entonces por lo que anota Agustín (1749: 197-198):

También es bueno para que las uvas sean grandes, y gruesas, ir a ellas en el mes de mayo, y con unas tijeras cortarles todos los cordeles que han hecho los sarmientos de la vid, o parra, y los que adelante se harán, porque como los sarmientos de sí no tienen sustento, desean mucho agarrar los dichos cordeles con cualquier cosa para sustentarse, y ponen tanto su virtud en dichos cordeles, como en el mismo fruto; y quitados, la virtud que iba a ellos va a las uvas. 
Y, por último, al final de este capítulo primero, se indica cuándo y cómo se han de coger las uvas para conservar.

Las uvas para conservar, se deben coger en luna vieja, que no sean demasiado maduras, y en día claro, y enjuto; dice Palladio, que el mejor tiempo de cortarlas para que se conserven, es entre el mes de agosto y septiembre (Agustín, 1749: 198).

El capítulo segundo se titula «Secretos de ingerir las vides de las viñas y parrales, de sus enfermedades y remedios y otras particularidades». Además de lo anunciado en el título, en este capítulo también se habla de los avisos para saber si habrá buena o mala cosecha y de cómo conservar las uvas en la misma planta.

Se explica cuándo ingerir (injertar) las viñas y cómo seleccionar los sarmientos ypúas:

El tiempo bueno para ingerir ha de ser en la primavera cuando los hielos han pasado, en el cual tiempo se podan las vides y empiezan a llorar, y entonces tomaréis los sarmientos para ingerir, y escogiendo los redondos de varilla, y macizos, y que tengan los botones cercanos los unos de los otros, cada púa para ingerir, que tenga también dos, o tres botones cada púa, de las que querréis ingerir encima de tierra, y las que querréis ingerir baxo de tierra, deben tener tres o cuatro (Agustín, 1749: 198).

Se explica cómo se hace el injerto con barreno:

También se hace con la vid en el ingerto con barreno; pero en las viñas deben estar las dos vides cercanas; es a saber, la vid que querréis ingerir, con la que querréis hacer el ingierto, y en los parrales de la misma manera, y este modo de injerir, haréis de la misma manera que se ha dicho en el segundo libro, del ingerir con barreno (Agustín, 1749: 199).

Efectivamente en su libro segundo (Agustín, 1749: 152) se explica cómo se hace un agujero en el tronco o rama del árbol y una rama del árbol vecino se introduce en él. Al cabo de dos años se corta la rama y el árbol injertado por su parte superior, entendemos que será para que se desarrolle la parte injertada.

Se indica cómo conseguir uvas tempranas, para ello se puede injertar la vid en un cerezo: «Haréis que una vid haga las uvas tempranas, sin ingerís la vid con un cerezo con barreno, estando el cerezo cerca de la vid» (Agustín, 1749: 199). 
Se pasa a continuación a las enfermedades de la vid. Se comienza con el piojo, del que se dice cómo combatirlo.

Las vides y sus sarmientos no criarán piojos si les untáis la corteza del tronco con gordura de oso y lo mismo haréis si untáis de la misma gordura el instrumento con que cortáis los sarmientos en el tiempo de la poda; $y$ otros dicen que con ajo y aceite (Agustín, 1749: 200).

Otro remedio es el de untar los instrumentos de poda con el resultado de hervir orugas con aceite, con «gordura de cabrón» o «sangre de ratón» (Agustín, 1749: 200).

Otro de los males es la helada. Para combatirla se recomienda «echar ceniza de cualquier manera por encima de las vides, después de ser podadas» o encender estiércol en la viña y «el humo irá desparciendo la helada (Agustín, 1749: 200).

Las vides están enfermas cuando las hojas se vuelven coloradas. En ese caso Agustín (1749: 201) expone varios remedios: regarlas con agua de mar, con orina humana o echarles ceniza de sarmientas. Las hojas descoloridas son síntoma de que la vid es débil, lo que se puede combatir ungiendo la cepa con ceniza mezclada con vinagre fuerte (Agustín, 1749: 201).

Cuando la lágrima es excesiva se considera una enfermedad. Hoy está demostrado que no es tal, que la emanación de la savia por los cortes de poda no produce ningún perjuicio a la cepa. Para combatir este exceso se recomienda cortar la corteza en las partes bajas del tronco de la cepa (Agustín, 1749: 201).

Otro problema o enfermedad es el de las uvas que se corrompen antes de madurar. Para curar estas uvas se aconseja las hojas de verdolaga, su zumo o poner en las raíces ceniza.

Tras las enfermedades se señala cómo saber si habrá buena cosecha. Para ello se puede coger un grano de uva y menearlo con dos dedos muy ligeramente y «si saliere algún licor, denotará que habrá abundancia de vino; y conoceréis si será bueno y poderoso» (Agustín, 1749: 201). Esto será cuando haya abundancia de lluvias en el invierno. Por el contrario, si hay lluvias en las vendimias el vino será «no tan solamente flaco, pero aún de poca sustancia y que hará muchas heces» (Agustín, 1749: 201).

Se explica después cómo conservar las uvas de los parrales para que estén frescas, haciendo un hoyo próximo donde quedarán tapadas sin corromperse hasta el invierno o introduciéndolas en un vaso de vidrio de cuello estrecho cuando las uvas estén en flor (Agustín, 1749: 201). 
Para espantar a las avispas y abejas de las uvas da un buen número de remedios, como rociarlas con estiércol de palomas mezclado con aceite común (Agustín, 1749: 203). Se puede proteger las uvas con papeles o trapos de lienzo:

Otros defienden las uvas de los parrales, envolviendo las uvas con papeles, y otros con trapos de lienzo, y eso es mejor, porque el papel en lloviendo se hace pedazos, y sería trabajo haber de volver a poner otros así a menudo (Agustín, 1749: 203).

El capítulo tercero se titula «Secretos de la cogida de las uvas, hacer el vino y su conservación». En él se explica: la vendimia, la elaboración del vino, cómo catar, las enfermedades del vino y su valor medicinal.

Comienza indicando cuáles son los indicios que marca el momento óptimo para la recogida de las uvas:

[...] las cuales no se deben coger, que no estén bien maduras, y esto conoceréis cuando las uvas fueran negras, y cuando la labor sea seca, y se despaja del grano, quedando limpio, sin tenerse nada con él, separándose de la pulpa, exprimiéndolas; o también si después de haber quitado un grano o dos de la raspa, o pezón de la uva, veis aquel lugar, que ocupaban dichos granos no se disminuye nada, antes queda de la misma manera, sin ocuparle los otros granos (Agustín, 1749: 203).

Se explica lo necesario antes de comenzar a «cortar las uvas»:

[...] conviene tener apercibidos todos los instrumentos, y vasos, como son cestos, cuchillos bien afilados para cortar las uvas, y las portadoras estén bien fornidas de cercos, y ataduras, y bien restriñidas, para que no se les vaya el mosto, y las tinajas, y otros vasos para lo mismo: las cubas y vasos haréis también estén fornidos de cercos, y ataduras, y el limpiar de ellos no sea hasta el día, o el día antes de poner el vino [...] (Agustín, 1749: 204).

Explica muy rápidamente y sin precisar cómo «sacar las raspas»: «En el recoger las uvas conviene sacar las raspas, hojas verdes, y los granos verdes, secos y marchitos de entre los maduros y enteros, porque no hagan daño en el vino» (Agustín, 1749: 204). Se sirve de una expresión y no recurre a un tecnicismo. 
Sin explicar el pisado de la uva, se pasa directamente a decir cómo se hace el vino. La descripción es muy básica y defiende como bueno lo que no es, pues remover las uvas durante la vinificación es muy conveniente.

De cómo se hace el vino en la tina o tinaja, se hace en diferentes maneras, como en este Condado de Rosellón: Puestas las uvas bien pisadas, nunca las mueven; y en el Principado de Cataluña veo, que todo el tiempo que las uvas y vino están en la tina o tinaja, todas las mañanas y tardes, menean todas las uvas; de tal manera que todo lo de arriba va abajo y lo de abajo a arriba, y no lo tengo por acertado [...] (Agustín, 1749: 204).

De la bodega se explica su ubicación:

La bodega debe estar puesta a la parte del septentrión, separada de toda suerte de mal olor, ni de ningún género de estiércol, ni dentro de la bodega pondréis ninguna manera de cosa, que tenga mal olor, como quesos, ajos, aceite, coles, ni otras cosas semejantes; porque no hay cosa que más haga corromper el vino, principalmente el vino nuevo (Agustín, 1749: 204-205).

Pasa a continuación a explicarse diferentes tipos de vinos, según su elaboración. Aquí observamos mayores índices de densidad terminológica. El primero que se explica es el que Miguel Agustín llama vino de pie. Se trata de un vino blanco obtenido a partir de uvas tintas, lo que hoy llamamos un «blanc de noir». Nada más pisarlo, «hecho el pie», se lleva a las cubas, de manera que no puede macerar con la piel que es la que da el color al vino. Del texto siguiente se deduce que la fermentación y maceración de este tipo de vino se lleva a cabo en las tinas.

De las uvas negras se hace un vino muy claro, que se llama vino de pie, porque luego que las uvas son pisadas, lo ponen en las cubas; sin estar en la tina; y este vino hace muchas heces, y se debe trasponer, o trascolar en luna vieja del enero, en día claro: Ese vino es muy crudo, y malo de digerir en el estómago, y no se debe beber, que no sea añejo, porque entonces es mejor para el estómago (Agustín, 1749: 205).

A continuación, se explica el vino clarete, que cuenta con una amplia sinonimia:

Hay otro vino clarete, que se llama de tres noches, y por otros nombres, de pasto, de ojo de perdiz, y de mujeres paridas; y este se saca de la tina, o tinaja, y 
después que ha hervido en ellas tres días, y tres noches; y esto es en los años que el tiempo de las vendimias anda enjuto ${ }^{3}$; porque los años que dicho tiempo va húmedo, se debe aguardar cuatro o cinco días y noches (Agustín, 1749: 205).

Llama la atención que aquí aparezca la voz vendimia, y no cuando se explica esta operación. Tinaja se usa como sinónimo de tina. Pensamos que la tina sería de madera y la tinaja de barro, con un mismo uso: fermentar y macerar el vino.

Señala la importancia de trasegar los vinos claretes y los blancos, para lo que usa la voz trasmudar:

[...] y este vino clarete, y todos los blancos, y todos los demás, que no se habrán acabado de hacer en el tinajón, o tinaja, es necesario trasmudarlos de las cubas en otras en el mes de enero, en día claro y enjuto y en la menguante de la luna, para sacar las heces que habrán hecho [...] (Agustín, 1749: 205).

$\mathrm{Al}$ vino tinto se le añade agua durante su elaboración. Así se explica su elaboración, que requiere varios días en la tina o tinaja:

En este tiempo, antes de hacer los claretes, se va entreteniendo la tina, o tinaja, refrescándola cada día, poniendo una carga o media de uvas con el mosto. Después de hechos dichos vinos claretes, ponen agua en la tina, o tinaja, por cada diez cargas de uvas que hay, media carga de agua, y después de la agua, si habrán hecho reserva de uvas, las pondrán con el mosto encima de la agua, sino sacarán del mosto de la tina por abaxo, y la volverán por encima de la agua, y se hará un excelentísimo vino tinto, dexándole hasta que esté hecho. Conoceréis que está hecho, cuando veréis que la tina no hierve, y el vino va nadando, y entonces colaréis el vino tinto [...] (Agustín, 1749: 205).

Se explica el remontado, el sacar el vino por abajo y echarlo por arriba, por la boca de la cuba, lo que permite mayor extracción de color. Lo que nos sorprende es que se añada agua, que resta calidad al vino y se podría hacer en el caso de que el grado de azúcar de las uvas fuera muy elevado, lo que no parece que en aquellos tiempos fuera lo más probable.

También se señala a continuación cómo se prensan las reliquias, lo que queda tras el pisado de la uva, y la extracción del vino.

Seco. 
[...] y luego si queréis prensar, sacaréis con la prensa el vino que estuviere empapado con las reliquias de las uvas, orujo o raspa, y este vino es muy bueno, tiene otra bondad, que se puede beber muy presto, porque está hecho dentro de quince días (Agustín, 1749: 205).

Si no se prensa, con lo que queda, lo que Miguel Agustín llama reliquias, se puede hacer las aguas, aunque no usa esta voz, que ya había incorporado con anterioridad Alonso de Herrera (1539: XLVI). Se trata de un vino de escasa calidad: «Si no queréis prensar, y queréis hacer vino para la familia, cada día le echaréis agua, según la cantidad de uvas, sacando también vino» (Agustín, 1749: 205-206).

Después se explica cómo se hacen otros tipos de vino. De los vinos blancos se dice tan solo que se hacen como el moscatel y el macabeo del que da más detalles:

Para hacer el vino moscatel, y macabeo, se han de coger las uvas bien maduras, y después dejarlas enjugar tres o cuatro días al sol o darles una torcida al tronco del racimo, cuando sean muy maduras, y que estén algunos días en las vides, hasta estar enjutas, y marchitas algún tanto, y después las vendimiaréis, y haréis el vino; y haréis que hiervan en la tina, seis hasta ocho días, porque cuando se hacen estos vinos un tanto en la tina, seis hasta ocho días, son mejores, y más sanos (Agustín, 1749: 206).

Se trata de vinos dulces hechos a partir de uvas parcialmente pasificadas por exposición al sol una vez vendimiadas o por doblez del pezón del racimo en la cepa, según se explica.

Del vino griego se dice que se hace con las uvas griegas que por lo general están conducidas en árboles, lo que en el pasado era habitual.

El vino griego se hace de las uvas de las vides llamadas griegas. Estas vides de ordinario están plantadas en los pies de álamos negros u de otros árboles, y los sarmientos de dichas vides están conducidos y puestos arriba por los troncos de los ramos de dichos árboles, y estos están puestos en praderías, y lugares húmedos, y nunca vienen a sazón con perfección, y así requieren modo diferente (Agustín, 1749: 206).

Se explica cómo se hace este vino y cómo se resuelven sus problemas de fermentación, causados por su forma de conducción y por estar cultivados en tierras frescas que imposibilitan una correcta maduración. El remedio se sigue utilizando hoy en día. Consiste en hervir una porción de vino, para provocarle la fermentación y echarlo a continuación a las demás cubas para que promueva la fermentación de estas. 
En hacer este vino se tiene esta orden; cogidas dichas uvas, haréis el vino, como está dicho del blanco; y puesto en las cubas, reservaréis de ello en una cuba pequeña, para que cuando conociereis que va perdiendo el hervor, hagáis hervir el dicho mosto reservado, con un buen vaso, e hincharéis las cubas de dicho vino griego, todo lo que habrá disminuido hirviendo en las cubas, así como saldrá del fuego; y con aquel calor volverá otra vez a hervir más recientemente, y esto es remedio para quitar aquella verdor del vino, por razón de las uvas, que eran un tanto verdes, y de esta misma manera se debe hacer de los vinos blancos, cuando las uvas son de viñas jóvenes. Este vino se debe trasportar en otra cuba, así como esta dicho del clarete y blanco (Agustín, 1749: 206).

De interés resultan los fragmentos que se ocupan de cómo catar, operación que Miguel Agustín llama gustar: «Cuando querréis gustar el vino de una cuba, aconseja Heziodo ${ }^{4}$, que la pipéis, o hagáis agujero en el medio de la cuba» (Agustín, 1749: 206). Más adelante se explica en qué casos y en qué circunstancias se debe gustar: «Cuanto en el gustar del vino para vender, o para beber, o para ver si tuviera algún sentimiento de corrupción, u de otro gusto, aconseja, que sea cando hace viento del norte, porque en ese tiempo el vino es más limpio y purgado» (Agustín, 1740: 207). El viento del norte significa frío, y con el frío el vino se estabiliza y se queda sin impurezas. Sin embargo, otros aconsejan hacerlo con viento del mediodía, es decir, con calor. Al aumentar la temperatura el vino tiende a mover, a desestabilizarse y esto es «demostración de lo que tiene en sí» (Agustín, 1740: 207). También se detalla cómo tiene que ser el gustar.

En cualquier manera de estas, conviene que sea en ayunas, por lo que entonces el gusto está sano, y no es bueno después de haber bebido otro vino, ni después de tener el estómago lleno; ni el que gusta el vino no debe haber comido cosa agría, salada, amarga, ni cosa que pueda mudar el gusto, solo debe haber comido un poquito, con que aún no lo haya digerido (Agustín, 1749: 207).

Tras estrujar las uvas se obtiene su zumo, el mosto. Si se quiere consumir así, debe evitarse la fermentación que lo transformaría en vino. Miguel Agustín explica cómo hacerlo, aunque el método que propone desde la perspectiva actual parece poco riguroso.

El mosto clarificaréis dentro de veinte y cuatro horas sin hervir, para poder beber luego, haciendo varillas delgadas con una plana de carpintero, de madera de avellano, y ponerlas dentro la cuba de mostro (Agustín, 1740: 207).

4 Se refiere a Hesíodo. 
Tampoco parece muy riguroso el método de introducir una piedra: $\ll[. .$.$] que$ haréis perder el hervir al mosto, o vino nuevo dentro de la cuba, poniéndole dentro una piedra tosca [...]» (Agustín, 1740: 207). Suponemos que lo que se consigue con la piedra es enfriar el mosto y así evitar la fermentación. Si se quiere tener mosto para todo el año se dice que debe guardarse en un pozo perfectamente cerrado en un vaso durante treinta días.

Para acelerar que el vino nuevo se convierta en añejo se debe mezclar con hierbas:

Haréis que el vino nuevo se vuelva luego añejo, tomando la yerba corona de rey, regalicia, y estarabaca, de cada una tres onzas, aloes opatico, dos onzas, o polvorizadlo, y mezcladlo con el vino nuevo (Agustín, 1740: 207).

Se explica cómo saber si en el vino se ha introducido agua (Agustín, 1740: 208), cómo conseguir no emborracharse bebiendo mucho vino (ibíd.: 208) o cómo quitar la embriaguez: «El que fuere borracho, se le quitará la embriaguez comiendo acelgas, y almendras con miel, y de cuando en cuando que un poquito de vinagre» (Agustín, 1740: 208). También da las recetas para aborrecer el vino (ibíd.: 209), para que no se gaste el vino de la cuba (ibíd.), para que el vino de pie o clarete «sea bueno en breve tiempo» (ibíd.) y para que el vino no haga flores (ibíd.).

Además de las flores (ibíd.) se señala otras enfermedades del vino. Para el vino corrompido se dice que se puede resolver «tomando rábanos, y cortados a pedazos los iréis enfilando en un hilo, y los pondréis dentro de la cuba» (Agustín, 1740: 209-210). También se dan remedios para quitar el sabor ácido del vino, el agror (ibíd.: 210) o para el vino turbio y escaldado (ibíd.), con claras de huevo, lo que se sigue haciendo en la actualidad.

Remediaréis el vino turbio, y escaldado, tomando claras de huevo, y bien batidas, que estén como espuma, y después las dejaréis reposar hasta que las claras estén asoladas en el vaso, y entonces las pondréis en la cuba de dicho vino: advirtiendo, que a una carga de vino se deben poner las claras de dos docenas de huevos, y antes de hacer esto, debe estar la cuba abierta por espacio de un día, y una noche, para que salga el vapor malo (Agustín, 1740: 210).

También explica cómo corregir un vino áspero o con mal olor (Agustín, 1740: 211). Vuelve a hablar del vino turbio y de sus remedios, mostrando poco orden (ibíd.) y explica que con polvos de miel cocida se puede convertir el vino blanco en tinto. 
Viene después en este capítulo unos pasajes en los que se habla del valor medicinal del vino. Con anterioridad, del vino clarete ya se había dicho que «es muy saludable para el estómago» (Agustín, 1749: 205). Para sacar piedras y arena de la vejiga y para orinar se recomienda mezclar vino con la hierba conocida como vejiga de perro (Agustín, 1749:212). Para el estómago, para cámaras de sangre, para enfermedades de riñones y para hacer orinar recomienda el vino con membrillos (Agustín, 1740: 212). Para la flaqueza de estómago es bueno el vino con media onza de canela fina, jengibre blanco, clavo, pimienta larga y nueces moscadas (Agustín, 1740: 212). Para las calenturas y para hacer digerir los humores y sacarlos fuera es bueno el vino hipocrás, del que da varias recetas. También apunta recetas a base de vino para «mover el estómago», para el dolor de costado, para la dificultad de orina, para combatir la ictericia, hidropesía y calenturas, entre otras dolencias (Agustín, 1740: 214-215).

Al final del capítulo, se explica cómo hacer un vino como «si fuese malvasía» sin serlo y lo mismo para el vino griego, el vino moscatel y el vino clarete (Agustín, 1740: 213-214).

El capítulo cuarto lleva el título de «Discurso breve de la invención, naturaleza, facultades, diferencias y necesidades del vino». En este capítulo, de corte más teórico que los que le preceden, se define el vino, se habla de la cata y de las cualidades y bondades de los diferentes tipos de vino. No todo el capítulo está dedicado al vino, en su última parte se dedica al pan. El vino se define así:

No es otra cosa el vino, sino el zumo que sale de las uvas, estrujadas o pisadas en el lagar, con esta diferencia que antes de hervir es llamado mosto y después de haber hervido se llama propiamente vino (Agustín, 1740: 219).

Hay también consideraciones sobre la cata:

En los vinos se considera el color, gusto, olor, facultad y consistencia, de donde las diferencias principales de los vinos son tomadas. Cuanto en el color, el uno es blanco, el otro claro, entre blanco, y tinto, como color miel, o clarete, o tinto (Agustín, 1740: 224).

Se habla en términos generales de las cualidades y bondades de los diferentes tipos de vino. Sobre el vino blanco se dice:

El vino blanco, generalmente es de más tenue sustancia, que el tinto, y cuece, y digiere más fácilmente, y penetra más todo el cuerpo, provoca más las venas, pero es de menos nutrimiento. El blanco, que fuere sutil, y caliente, es más pronto que los otros en dañar la cabeza (Agustín, 1740: 224). 
Del vino tinto se dice que «es tenido por mejor de todos, porque dice Galeno, que los vinos tintos, y de grassa substancia, con poco trabajo están convertidos en la naturaleza de la sangre» (Agustín, 1740: 224). Y de los claretes se anota que son de «gruesa, y difícil decocción, y de digestión». Por ello se dice que «todos los vinos crasos, o sean claretes, o tintos alimentan, y engordan el cuerpo abundantemente, pero dan más pena, y trabajo en el estómago [...]» (Agustín, 1740: 224-225).

Este capítulo cuarto acaba hablando de las bondades del pan (Agustí, 1740: 226-228).

\subsection{Valoración del léxico de la vid y el vino}

Miguel Agustín organiza el conocimiento vitivinícola en torno a la plantación y el cultivo de la vid (capítulo 1 y 2), la vendimia y la elaboración del vino (capítulo 3) y una breve disertación teórica sobre esta bebida (capítulo 4).

Este conocimiento vitivinícola está lejos del recogido mucho antes por Alonso de Herrera (1539). Hay parcelas de este saber, como el relativo a la ampelografía, por el que Miguel Agustín pasa de largo. Cita cinco variedades, sin detenerse en explicar sus características: castellana, griega, malvasia (Agustín, 1749: 195), macabeo y moscatel (Agustín, 1749: 206). No se ocupa el tratadista catalán de la descripción de las variedades de vid, a las que G. Alonso de Herrera dedica un capítulo, el segundo. En dicho capítulo (Alonso de Herrera, 1539: XxirIr) se anotan y describen 15 variedades, entre las blancas: torrontés, moscatel, cigüente, jaén, hebén, alarije, vinoso, castellano blanco, malvasia y lairenes y entre las prietas (tintas): castellanas, palomina, aragonés y tortoçon y berrial.

El resto de conocimiento vitivinícola está en ambos tratados, pero el trato que le da Miguel Agustín es mucho más superficial. Así, por ejemplo, en lo relativo al arar y cavar las viñas, Miguel Agustín (1749: 196) despacha rápido el tema en menos de un párrafo del capítulo primero, anotando los tres momentos en los que hay que cavar la viña. Alonso de Herrera (1539: xxxvinIv), por su parte, dedica un capítulo al asunto dando muchos más detalles e identificando la segunda y tercera labor con nombres específicos, binar y terciar, respectivamente. La vendimia y la elaboración del vino son tratados en un mismo bloque por parte de los dos autores, pero es mucho más extenso Alonso de Herrera. Solo en la cata supera Miguel Agustín a Alonso de Herrera.

Otro aspecto que diferencia a ambos textos es su propio carácter, argumentativo en el caso de Alonso de Herrera y meramente informativo en el caso de Miguel Agustín. El tratado de Alonso de Herrera tiene un marcado carácter técnico, recurre a argumentos probatorios o demostrativos y argumenta sus técnicas, incluso opo- 
niéndose a alguna de las autoridades que cita (Ibáñez, 2010: 18-19 y 2020: 66-69). Cosa que no ocurre con la obra de Miguel Agustín, que se limita a trasladar un contenido sin espíritu crítico.

Como consecuencia de todo ello, se observa una mayor pobreza terminológica en el tratado de Miguel Agustín con relación al de Alonso de Herrera, aun siendo este anterior. Miguel Agustín, como queda patente en el punto anterior, recurre a voces de carácter genérico, con frecuencia se refiere a las suertes de vides, sin especificar las variedades, o a los sarmientos para explicar los utilizados para plantar una cepa, sin nombrar en este caso las voces especializadas cabezudo y barbado, ya utilizadas por Alonso de Herrera (1539: XXVIv). Se sirve de expresiones como «cogida de las uvas» o «cortar las uvas» en lugar de decir vendimiar, que sí cita en otros casos. Se dice «sacar los raspones» para separar el grano del raspón (Agustín, 1749: 204), actividad para la que Alonso de Herrera (1539: XLIIIr) ya utilizaba la voz descobajar. Miguel Agustín llama «vino para la familia» al que se hace añadiendo agua a la uva prensada y que Alonso de Herrera (1539: XLVIv) ya denominaba aguas, término que Miguel Agustín parece desconocer.

Apenas existe conciencia en Miguel Agustín de que se encuentra ante una lengua de especialidad y no acostumbra a explicar o matizar los términos que usa. Tan solo hay un caso en el que parece plantearse el asunto, cuando aclara la diferencia entre majuelo y viña: «Los que querrán plantar viñas, que algunos llaman majuelos, todo el tiempo que están en juventud, después que son viejas las llaman viñas» (Agustín, 1749: 195). Sin embargo, Alonso de Herrera es consciente desde el prólogo de ser el primero en escribir sobre agronomía en castellano y de la dificultad que esto entraña.

Cabe preguntarse, por otro lado, si Miguel Agustín toma o no voces especializadas de la corriente inaugurada con anterioridad por Alonso de Herrera. Sí que lo hace, pero no son muchas, en total 21. Lo que representa un $20 \%$ del total de las voces del vino de Miguel Agustín. Son las siguientes: agraz, agrazón, cesto, flores, heces, hervir, injerir, lagar, lloro, moscatel, mosto, mugrón, pámpano, parral, pezón, pimpollo, podar, púa, suertes, trasegar y tinaja.

En la configuración de una lengua de especialidad la vacilación en el uso de denominaciones distintas es habitual hasta que alguna de ellas se consolida. Esta inestabilidad terminológica está presente en Miguel Agustín. Para llamar a lo que queda tras el estrujado de las uvas usa tres sinónimos: reliquias, orujo o raspa (Agustín, 1749: 205). Para explicar la operación de pasar el vino de un depósito a otro para afinarlo llega a utilizar cuatro formas distintas: trascolar, trasmudar, trasponer y trasegar. De todas ellas la que ha triunfado ha sido trasegar, también utilizada por Alonso de Herrera. Sorprende el número de nombres que recibe el 
vino clarete (Agustín, 1749: 205): vino de tres noches, vino de ojo de perdiz y vino de mujeres paridas. Se le llama vino de tres noches, seguramente por el tiempo que pasa fermentando con la piel, llegando a un tinto con poco color, posiblemente el del ojo de perdiz, que es otra de las denominaciones que recibe. Es la primera vez que encontramos la denominación vino de mujeres paridas, y tal vez sea, aunque no lo podemos confirmar, porque se le daba de beber a las parturientas con fines medicinales.

Dado que se trata de un tratado traducido de un original catalán, que en realidad es traducción del francés, tal como se ha explicado, cabría esperar el uso de extranjerismos. Todo se reduce al uso del galicismo clarete, a la confusión vid/viña y al calco entretenimiento.

Es bastante probable que el término claret, más tarde clairet, utilizado por los comerciantes ingleses para llamar al vino tinto claro de Burdeos, sirviera en España para llamar al vino llegado de Francia en años de escasez, y después, por comparación, para denominar así a algunos vinos de Rioja de color parecido. El nombre penetra a través del Puerto de Bilbao con los vinos llegados desde Burdeos en el siglo XVII (Ibáñez, 2010: 18-19). Se inaugura así el influjo del francés en el español del vino, que de momento es tímido y que luego se va a convertir en un rasgo distintivo de esta lengua de especialidad.

Está presente en el tratado de Miguel Agustín la confusión vid/viña, que le viene seguramente del francés o del catalán: «La viña no se puede plantar de grano, porque serían las uvas agrazonas, y tardarían mucho en llevar fruto (Agustín, 1749: 194). Aquí se trata de la vid, la planta, y no de la viña, parcela plantada de vides. Ambas acepciones se recogen en francés en un solo término: vigne, al igual que en catalán vinya. Igual origen, francés (entretenir) o catalán (entretenir), puede tener entreteniendo que debería haberse traducido por manteniendo o conservando: «En este tiempo, antes de hacer los claretes, se va entreteniendo la tina, o tinaja, refrescándola cada día, poniendo una carga o media de uvas con el mosto» (Agustín, 1749: 205).

Por otro lado, sí observamos que hay voces de creación propia. El español de entonces, y aún más el que maneja Miguel Agustín, es una lengua pobre en terminología especializada, lo que le lleva en ocasiones a inventarlas. Así, por ejemplo, ocurre con la voz reliquias o cordel, y pensamos que también ocurre lo mismo con portadora. No las hemos visto documentadas en otros textos como voces específicas del vino. Para el caso de reliquias recurre al léxico religioso, que le queda tan cerca, y tal vez también para cordel, que Alonso de Herrera (1539: XXIXr) llama tiseruela y tenazeta. Portadora sería una voz de uso común a varios ámbitos, en particular en el agrícola, de la que se sirve. Como no conoce la voz descobajar, re- 
curre a voces propias de otras actividades agraria, como despajar (Agustín, 1749: 203), separar el grano de la paja, para referirse a la acción de separar el grano del raspón. Ninguno de estos términos de cosecha propia ha pervivido como voz especializada del vino.

El nivel técnico se eleva cuando Miguel Agustín trata del gustar, de la cata, en la que dice se tiene que tener en cuenta: «el color, gusto, olor, facultad y consistencia» (Agustín, 1740: 224). Aquí hay una mayor densidad terminológica: pipear, gustar, limpio, purgado, áspero, bastardo, añejo, crudo, suave, verde, fuerte, potente, delicado, etc. También la hay en los tipos de vino según su elaboración: vino de pie, clarete, vino de tres noches, vino de pasto, vino de ojo de perdiz, vino de mujeres paridas, tinto, blanco, moscatel, macabeo y griego.

\section{CONCLUSiones}

El libro de Miguel Agustín, escrito en catalán con el título Secrets de agricultura, casa rústica y pastoril, se publicó por primera vez en Barcelona en 1617. Su propio autor, años más tarde, en 1626, lo vierte y publica en español, con el título de Libro de los Secretos de agricultura, casa de campo y pastoril traducido de lengua Cathalana en Castellano, añadiendo un quinto libro, otras curiosidades y un vocabulario en seis lenguas. Con el paso del tiempo esta traducción en castellano conoció un gran número de ediciones, hasta veinte; sin embargo, la primera edición en catalán no se volvió a reeditar.

Esta traducción castellana es en realidad la traducción de una traducción, pues el original catalán no es tal. Es en su mayor parte la traducción sobre todo de la obra francesa de agricultura titulada L'Agriculture et maison rustique de Charles Estienne y Jean Liébault.

El libro de Miguel Agustín tiene una doble función: por un lado, es un libro práctico sobre la agricultura, los animales y la gestión de una casa de campo, y, por otro, es un libro doctrinal que defiende un modelo de vida agrícola acorde con las creencias cristianas.

El conocimiento vitivinícola está lejos del recogido mucho antes por Alonso de Herrera, al que no cita. De ahí que haya mayor pobreza terminológica en la obra de Miguel Agustín. Este recurre a voces genéricas y no específicas, tal vez porque sencillamente las desconoce. Sus fuentes son escritas. No hay evidencias de que tome voces del registro oral, como en su día hizo G. Alonso de Herrera.

Entre el primer español del vino fijado con el libro segundo de la Obra de agricultura de 1513 de G. Alonso de Herrera y finales siglo XviII y primera mitad del 
XIX, cuando aparece un vocabulario más técnico con importantes aportaciones llegadas desde Francia, la lengua de la vid y el vino no experimenta cambios importantes. Podríamos hablar, a la luz del tratado de Miguel Agustín, de un período de cierto estancamiento. Su tratado, aunque parcialmente, es continuación de la corriente iniciada por G. Alonso de Herrera y sus aportaciones a esta lengua de especialidad no son significativas. Introduce voces nuevas (reliquias, cordel, portadoras y despajar) que no llegan a cuajar como neologismos en el español del vino posterior. Su mayor aportación está en el ámbito de la cata y en los diferentes tipos de vinos en los que muestra mayor riqueza terminológica.

A pesar de que el original en catalán de Miguel Agustín es en su mayor parte traducción del francés, no abundan los galicismos, salvo el caso de clarete, que, eso sí, marca el punto de partida de la influencia gala en el español del vino. En el siglo XVII no hay en el español del vino un influjo externo reseñable. Habrá que esperar hasta finales del siglo XVIII para que este comience a ser relevante.

\section{Bibliogr afía}

Agustín, Miguel (1617): Llibre dels secrets de agricultura casa rústica y pastoril, Barcelona, Esteve Lliberós.

Agustín, Miguel (1626): Libro de los secretos de agricultura, casa de campo y pastoril, Perpiñán, Luis Roure.

Agustín, Miguel (1749): Libro de los secretos de agricultura, casa de campo y pastoril, Barcelona, Pedro Escuder.

Agustín, Miguel (1998 [1617]): Llibre dels secrets de agricultura, casa rústica y pastoril, ed. facsímil, Barcelona, Altafulla.

Agustín, Miguel (2007 [1617]): Llibre dels secrets de agricultura, casa rústica y pastoril, ed. facsímil, Villafranca del Penedès, Edicions Propostes Culturals Andana.

Alonso de Herrera, Gabriel (1539): Libro de agricultura, Alcalá de Henares, Joán de Brocar.

Antón Ramírez, Braulio (1865): Diccionario de bibliografía agronómica y de toda clase de escritos relacionados con la agricultura, seguido de un indice de autores y traductores con algunos apuntes biográficos, Madrid, Impr. y Est. de M. Rivadeneyra.

Bibliotheca Magica (2007): Catálogo de la exposición realizada en la Biblioteca Histórica, Madrid, UCM. 
Estienne, Charles y Jean Liebault (1594): L'Agriculture et maison rustique, Lyon, Jacques Roussin. En línea: <https://books.google.es/books?id=pMnMB$9 \mathrm{bl} 3 \mathrm{wcC} \& \mathrm{hl}=\mathrm{es}>[20 / 03 / 2020]$.

Estienne, Charles y Jean Liebault (1597): L'Agriculture et maison rustique, Genève, Gabriel Cartier. En línea: <http://dx.doi.org/10.3931/e-rara-6831> [28/03/2020].

IbÁÑEz Rodríguez, Miguel (2010): 43 palabras de la vid y el vino, Logroño, Gobierno de La Rioja.

IbáÑez Rodríguez, Miguel (2017): «L'art de faire le vin y su traducción al español: la gestación de un primer vocabulario técnico del vino (1786-1845)», Hikma: estudios de traducción, 16, pp. 9-33.

IbÁÑEz Rodríguez, Miguel (2020): «El libro segundo de la Obra de agricultura de 1513 de Gabriel Alonso de Herrera. En los orígenes del español del vino», en Miguel Ibáñez Rodríguez (ed.), Enotradulengua. Vino, lengua y traducción, Berlín, Peter Lang, pp. 61-81.

LunA-BATLLE, Xavier (2013): «El Llibre dels secrets d'agricultura casa rústica ipastoril (1617) de Miquel Agustí: un llibre no del tot obert», Manuscrits. Revista d'Historia Moderna, 31, pp. 65-87.

Luna-Batlle, Xavier (2015): «Els Secrets d'agricultura (1617) de Miquel Agustí en el context dels llibres agronòmics europeus», Manuscrits. Revista d'Història Moderna, 33, pp. 17-32.

Luna-Batlle, Xavier (2017): «Els Secrets d'agricultura de Miquel Agustí (1617): fonts i llengua», en Manuel Pérez Saldanya y Rafael Roca Ricart (eds.), Actes del Dissetè Col.loqui Internacional de Llengua i Literatura Catalanas, Asociació Internacional de Llengua i Literatura Catalanes, Institut d'Estudis Catalans, pp. 111-124.

Pablo NuñEZ, Luis (2007-2008): «Ediciones e historia textual del Libro de los secretos de agricultura de Miguel Agustín», Butlleti de la Reial Acadèmia de Bones Lletres de Barcelona, LI, 199-223.

Quirós García, Mariano (2015): «El Libro de Agricultura de Gabriel Alonso de Herrera: un texto en busca de edición», Criticón, 123, pp. 105-131.

Serres, Olivier de (1611): Le théâtre d'agriculture et mesnage des champs, Genève, Jamet Métayer.

Soberanas, Amadeu Jesús (1988) «Les edicions del "Prior"》, en Llibre dels secrets d'agricultura, casa rústica i pastoril, Barcelona, Alta Fulla, pp. 39-45. 


\section{Anexo I: Glosario}

Agraz: uva verde.

Agrazón: uva que no llega a madurar, uva verde; voz formado a partir de agraz.

Agror: acidez del vino.

Aloque: vino tinto claro.

Arrope: mosto cocido y concentrado al que se le puede añadir frutos secos.

Boca: espacio abierto de la parte superior de la cuba por el que se introduce o se saca el vino. También se le llama ojo.

Bodega: lugar donde se hace el vino.

Botón: yema de brotación; también se le llama ojo.

Cántaro: recipiente pequeño para contener vino u otros líquidos.

Carga de uva: cantidad de uva que puede trasportar una bestia, entre 150 y $200 \mathrm{~kg}$.

Carga de vino: el vino que se puede hacer con una carga de uva, entre 7 y 10 cántaras.

Castellana: variedad de vid.

Cerco: aro de hierro que sujeta por presión las tablas de las portadoras.

Cesto: recipiente para la recogida de la uva durante la vendimia.

Clarete: vino que fermenta parcialmente con los hollejos.

Clarificar: proceso que permite por decantación que las partículas e impurezas del vino se desplacen al fondo de la cuba y así quede limpio.

Cordel: órgano delgado y voluble del que se sirve la vid para asirse a cualquier elemento de su proximidad para trepar. Hoy se llaman zarcillo.

Cuba: depósito para guardar y conservar el vino en la bodega.

Flores: enfermedad del vino que se manifiesta cuando se crea un velo en la superficie del mismo.

Griega: variedad de vid.

Gustar: probar el vino para analizar sus bondades o defectos.

Heces: lo que se deposita por decantación en el fondo de la cuba durante la fermentación.

Hervir: cuando el mosto se trasforma en vino. Hoy se dice fermentar.

Ingerir: implantar un trozo de sarmiento (púa) con una o más yemas en otro. Hoy injertar.

Ingerto con barreno: injerto consistente en introducir un sarmiento en la cepa vecina.

Ingierto: trozo de sarmiento o púa con una o más yemas que se implanta en otro. Hoy injerto.

Lagar: lugar donde se hace el vino.

Lloro: savia que se derrama en primavera por los cortes de poda en días calurosos.

Macabeo: variedad de vid y el vino dulce que se hace de ella.

Majuelo: viña joven. Hoy se emplea indistintamente viña y majuelo, aunque esta última apenas se usa.

Malvasía: variedad de vid.

Moscatel: variedad de vid y el vino dulce que se hace de ella. 
Mosto: el zumo de la uva sin fermentar. Mugrón: sistema de plantación consistente en enterrar una rama de una cepa hasta que genere raíces y se convierta en otra nueva. Hoy se llama acodo.

Ojo: yema de brotación a la que se denomina igualmente botón y yema. También se llama así a la boca o espacio abierto de la parte superior de la cuba.

Ollejos: lo que queda de las uvas una vez estrujadas para obtener el vino. También se le llama orujo, reliquias y raspa.

Orujo: lo que queda tras el pisado de la uva y una vez sacado el vino. También se le llama ollejos, reliquias y raspa.

Pámpano: rama tierna de la vid que con el agostamiento se convierte en sarmiento.

Parral: viña conducida con maderas o en un árbol, por lo general plantadas en tierras fértiles.

Pezón: rama pequeña que sostiene el grano de uva en el racimo.

Pimpollear: eliminar en primavera los brotes de la madera vieja, para favorecer el desarrollo de los pámpanos. Hoy espergurar.

Pimpollo: Brote tierno de la madera vieja de la vid, que en primavera se quita.

Piojo: enfermedad de la vid.

Pipa: cuba o tonel de vino.

Pipear: sacar una pequeña muestra de vino de la cuba.
Podar: eliminar o cortar parcialmente ciertas partes de la vid para favorecer un óptimo desarrollo de la misma.

Portadora: recipiente para el trasporte de la uva de la viña a la bodega.

Púa: trozo de sarmiento con una o más yemas que se implanta en otro para injertarlo.

Pulpa: parte interior y carnosa del grano de uva.

Raspa: estructura del racimo de la que penden los granos.

Reliquias: lo que queda tras el pisado de la uva y una vez sacado el vino. También le llama orujo.

Sarmiento: el que se usa para plantar una cepa. Hoy no se usa con esa acepción sino con la de pámpano agostado y seco.

Suerte: variedad de vid.

Tina: recipiente en el que se vinifica, fermenta y macera el vino.

Tinaja: recipiente de barro cocido para guardar el vino en la bodega. A veces se usa como sinónimo de tina.

Tinajón: nombre que se aplica a la tina donde fermenta y macera el vino.

Trascolar: pasar un vino de un depósito a otro para afinarlo. También le llama trasmudar, trasponer, y trasegar.

Trasmudar: pasar el vino de una cuba a otra para afinarlo. También le llama trascolar, trasponer y trasegar.

Trasponer: pasar un vino de un depósito a otro para afinarlo. También le llama trascolar, trasmudar y trasegar. 
Trasegar: pasar un vino de un depósito a otro para afinarlo. También le llama trascolar, trasmudar y trasponer. Uva: fruto de la vid.

Vaso: recipiente pequeño para guardar el vino en la bodega.

Vendimia: recolección de la uva.

Vinaza: el vino que se saca de las heces y posos.

Vino: el mosto de la uva fermentado.

Vino añejo: el de varios años.

Vino áspero: el que lo es al paladar.

Vino bastardo: el vino que se hace con uvas pasas.

Vino blanco: el que tras el pisado y prensado fermenta sin entrar en contacto con la piel.

Vino cocido: el que ha fermentado.

Vino crudo: vino poco evolucionado y que por ello está tieso.

Vino de acarreo: a falta de vino local, el que viene de fuera.

Vino de mujeres paridas: nombre que se da también al vino clarete, tal vez por recomendarse a las parturientas.

Vino de ojo de perdiz: así se llama también al clarete, por su color.

Vino depasto: vino común, corriente. $\mathrm{Al}$ clarete también se le llama así.
Vino de pie: vino blanco obtenido de uvas tintas.

Vino de tres noches: nombre con que también se llama al vino clarete, tal vez porque ese es el tiempo que pasa macerando con los hollejos.

Vino dulce: el que tras fermentar conserva parte del azúcar del mosto.

Vino escaldado: el que no está clarificado.

Vino griego: el elaborado a partir de vides griegas.

Vino hipocrás: bebida a base de vino, azúcar y diferentes hierbas para la curación de las calenturas.

Vino limpio: vino bien clarificado, sin impurezas.

Vino nuevo: el del año.

Vino purgado: vino purificado, limpio.

Vino suave: el que lo es al paladar.

Vino tinto: el que macera más tiempo con el hollejo hasta colorearse.

Vino turbio: el que no está clarificado.

Vino verde: el vino que conserva sus sabores iniciales de acidez elevada.

Viña: parcela plantada de vides.

Viñadero: el que cultiva la vid.

Yema: brote de la vid. También le llama ojo y botón. 0

Fecha de recepción: 30 de julio de 2020 Fecha de aceptación: 3 de septiembre de 2020 